\title{
Land managers' behaviours modulate pathways to visions of future land systems
}

\author{
Calum Brown $^{1}$ - Sascha Holzhauer ${ }^{1} \cdot$ Marc J. Metzger $^{1} \cdot$ James S. Paterson $^{1}$ • \\ Mark Rounsevell ${ }^{1}$
}

Received: 20 July 2015/Accepted: 5 June 2016/Published online: 24 June 2016

(c) The Author(s) 2016. This article is published with open access at Springerlink.com

\begin{abstract}
Attempts to influence the development of land systems are often based on detailed scenarios that constrain relevant factors, describe a range of divergent but plausible futures and identify potential pathways to visions of desirable conditions. However, a number of assumptions are usually made during this process, and one of the most substantial is that land managers display homogeneous, economically rational behaviour across space, time and scenarios. This assumption precludes the consideration of important behavioural effects and limits understanding of the feasibility of scenario-based pathways towards visions. We use an agent-based land use model to examine broad forms of behavioural variation within defined scenarios in theoretical contexts. We relate model results to stakeholder-developed visions of desired future land systems in Europe and so assess the scope for behavioural pathways towards these normative futures. We find that the achievability of visions is determined by internal inconsistencies,
\end{abstract}

Electronic supplementary material The online version of this article (doi:10.1007/s10113-016-0999-y) contains supplementary material, which is available to authorized users.

Calum Brown

calum.brown@ed.ac.uk

Sascha Holzhauer

sascha.holzhauer@ed.ac.uk

Marc J. Metzger

marc.metzger@ed.ac.uk

James S. Paterson

james.paterson@ed.ac.uk

Mark Rounsevell

mark.rounsevell@ed.ac.uk

1 School of GeoSciences, University of Edinburgh, Edinburgh EH8 9XP, UK scenario conditions and the multifunctional potential of land uses, with a fundamental tension between large-scale land use productivity and small-scale diversity (i.e. land sparing and land sharing). Trading conditions affect this balance most strongly and represent an obvious target for governance strategies concerned with achieving multifunctional land use. However, within specific circumstances behavioural effects are strong and diverse, and can accelerate, counteract or mitigate the impacts of other drivers. This suggests that visions for the land system should focus on trade-offs, identifying those that are least strong, most acceptable and most susceptible to adjustment through behavioural or other influences.

Keywords Agent-based modelling - Scenario - Climate change $\cdot$ Land use - Multifunctional - Stakeholder engagement

\section{Introduction}

Attempts to explore, predict or influence the development of the land system are subject to a number of substantial uncertainties. These uncertainties reflect the complex, interactive nature of the various human and natural systems that impact upon the land system, and the fact that none of these systems are fully understood. Climatic, environmental, social, political, economic and other changes are all known to have strong effects, but their form and magnitude cannot be easily anticipated (e.g. Hansen et al. 2001; Gotts 2007; de Chazal and Rounsevell 2009; Phalan et al. 2011).

Nevertheless, it is precisely these uncertainties that make improved understanding of the land system a priority. In particular, knowledge of how changes in climatic, 
demographic and consumption patterns might affect land use is crucial to the design and implementation of strategies to maximise human and environmental wellbeing (IPCC 2012). Without such knowledge, reactive management of the land resource is unlikely to adequately support human or natural systems and may result in sudden and irreversible changes in the functioning of global ecosystems (Barnosky et al. 2012).

Uncertainties about the dynamics of the Earth system are not easy to constrain and are at some level entirely intractable (Rial et al. 2004; Knutti and Sedlacek 2013). As a result, methods to minimise and to explore these uncertainties have been developed concurrently. Projections of future conditions are now generated by a large number of climatic, ecological and land use models, increasingly operating in concert (e.g. Rowlands et al. 2012; Harrison et al. 2015). Such models may be validated against historical data and used to quantify some forms of uncertainty, but they cannot address many important factors. As a result, they are usually applied within detailed climatic or socio-economic scenarios that describe a range of divergent but plausible future conditions (Rounsevell and Metzger 2010; Kriegler et al. 2012; Dubrovsky et al. 2015). However, scenarios cannot completely prescribe all relevant conditions without sacrificing their interpretability and relevance. Therefore, while scenarios and models together provide valuable evidence on which to base practical or political decisions concerning land management, an appreciation of uncertainties associated with scenario and model design remains crucial (Stainforth et al. 2007; Morgan and Keith 2008).

Because different scenarios and models have different purposes and designs, it is often possible to reduce uncertainties further by comparing results generated under different assumptions (Knutti and Sedlacek 2013). This technique clearly relies on the adoption of a diversity of approaches towards a common problem, and its application has been hampered to some extent by design convergence in models and scenarios (Morgan and Keith 2008; Metzger et al. 2010; Knutti et al. 2013). One of the most general assumptions made in scenarios and models concerned with the land system is that individual land managers display homogeneous, economically rational behaviour across space, time and scenarios. This assumption has enabled models to focus on macroeconomic drivers of land use change and to operate across large spatial scales, but may neglect a range of behavioural effects that could prove highly significant in shaping the land system (Rounsevell et al. 2014). For instance, spatial diffusion of agricultural knowledge and practice is thought to be an important factor in land use change (e.g. Berger 2001; Alexander et al. 2013), and individual-level behaviour in general may be key to the speed and spatial properties of changes in land management (e.g. Parker and Meretsky 2004; Evans et al. 2011). This is likely to be especially true where sudden changes or 'shocks' affect the land system (e.g. Filatova and Polhill 2012; Lambin and Meyfroidt 2010). It is therefore essential to account for behavioural effects during the development of pathways towards visions of desired future conditions.

However, behavioural effects are fundamentally complex and context-dependent, making them very difficult to assess. As a result, exploratory approaches that isolate and investigate particular behaviours provide a valuable basis for improved understanding (e.g. Magliocca et al. 2013; Brown et al. 2014). Here, we adopt such an exploratory approach, using an agent-based model of land use to explore broad forms of behaviour within defined climatic and socio-economic scenarios. We run a series of simulations in theoretical settings to isolate behavioural effects and to assess their dependencies on characteristics of the land system and social, environmental and economic contexts. We link model results to established visions of future land systems (Pérez-Soba et al. 2015) through a series of spatial and aggregate metrics describing land use and cover, allowing us to assess the extent to which simulations converge on specific criteria of the visions. On this basis, we examine the feasibility of the visions and identify factors that determine whether or not they can be achieved, including the relative potential roles of scenario and behavioural factors. Our findings are intended to provide a basis for further work that explores the impacts of human behaviour on the land system in theoretical and empirical contexts, so identifying behavioural pathways that can be targeted by novel governance strategies.

\section{Materials and methods}

\section{Model set-up}

Simulations were carried out using the 'CRAFTY' agentbased land use modelling framework (Murray-Rust et al. 2014). This framework allows the inclusion of several general forms of behaviour to represent the decisionmaking processes of individual land managers, as well as climatic and socio-economic drivers of land use change. Exogenous demands for ecosystem goods and services represent societal requirements and preferences, which vary as a result of demographic or socio-economic change and which are satisfied by behavioural agents that manage units of land and generate supply. These individual agents make land use decisions as a function of the levels of demand and supply, the behavioural characteristics of each agent and the (climate-dependent) productive potential of individual units of land. We also introduce social networks 
between agents to allow for the gradual dissemination of technological knowledge affecting agricultural yields. Network links are created according to an adapted forest fire approach (Lescovec et al. 2007) to account for community structures. This respects agent-type-specific affiliation preferences as well as typical distributions of link distances and pre-defined degree distributions. Further model details are given below and a full description can be found in Murray-Rust et al. 2014.

\section{Modelled 'worlds'}

In order to explore behavioural effects in isolated and controlled settings, we designed two simple but contrasting 'worlds' within each of which a common set of simulations was run. Each world comprised 40,000 equally sized grid cells $(200 \times 200)$, each of which represented a single land unit. Across these cells, we defined five capitals that described resource availability for production of goods and services: crop productivity, forest productivity, livestock productivity, infrastructure and economic capital. We also included a sixth capital, natural capital, to describe environmental quality. In the first world (World A), each capital took the form of a single gradient from a defined location at which that capital was maximised (with a value of 1.0). This had the effect of producing large, coherent areas of suitability for each land use. In the second world (World B), each capital was independently assigned ten local maxima at random locations in space, around which the same gradient operated as in World A. Values of each capital were summed and then normalised to cover the same range (0.0-1.0) as in World A. Capital variations across both worlds are shown in Figure S1.

These contrasting designs were not intended to closely mimic empirical productivity patterns, but to represent clear alternatives of dependent and independent capital distributions, so allowing us to assess the extent to which our findings were influenced by capital patterns rather than experimental or scenario characteristics. Nonetheless, the worlds had certain characteristics intended to give them real-world relevance. First, both were sufficiently large to allow considerable heterogeneity to develop in the modelled land systems without imposing unrealistically large differences between neighbouring cells, making them appropriate to the regional-scale visions considered. Second, the scales and dependencies with which the capitals varied within each world provided examples of both gradual, consistent changes in productivity (interpretable as the result of factors such as latitude or climate that vary over large spatial scales or of analysis over small geographical extents; World A) and more varied and diverse changes (interpretable as the result of factors that vary over smaller spatial scales, the interaction of unrelated factors that do not have constant relationships across space, or analysis over larger geographical extents; World B). The implications of these differences for our results are considered in Discussion section.

Both of the worlds were modelled as single land use systems and as two collections of independent systems ('regionalisations'). In the latter cases, the worlds were divided into 4 and 16 equally sized areas, each with its own level of demand (1/4 and 1/16th of total demand, respectively), which could only be satisfied by production within that area. These three treatments of the total area were used to represent systems with different trading arrangements, from entirely free trade across the land system to limited inter-regional trade and restricted intra-regional trade only (Brown et al. 2014). We also constrained agents' abilities to search for cells to compete for under limited trade to represent limitations to knowledge under closed systems (see Table S5, Online Resource 1 for details).

\section{Agents and land uses}

The worlds were populated with agents divided between seven types (defined according to the concept of Agent Functional Types; Arneth et al. 2014) representing broad forms of land use: intensive and extensive crop farmers, intensive and extensive livestock farmers, biofuel farmers, foresters and conservationists. Each agent type was able to produce one or more of a set of services for which demand levels were exogenously defined: cereal crops, meat, biofuels, timber and recreation. Production levels for each agent were determined via a typological Cobb-Douglas style function of capital levels (Murray-Rust et al. 2014) and adjusted under individual behavioural variations described below. Intensive agents were more productive than extensive agents, but were also more sensitive to capital levels and less able to produce multiple goods and services. We also modelled extensive agents and, especially, conservationists, to be more dedicated to their land use and therefore less willing to abandon or change the management of their land. Units of supply and demand were abstract and equivalent across services.

For each agent type, we parameterised two production functions describing average mono- and multifunctional productive ability. Under mono-functionality, each agent type was able to produce only a single service (representing an assumption that modelled land uses are entirely distinct), while multifunctionality allowed the production of recreation as a secondary service while reducing primary service productivity. We did not allow multifunctional production of other services because of the number of arbitrary assumptions about absolute and relative production levels that would be required; instead, we used the example of multifunctional production of recreation to 
explore the potential impacts of multifunctionality in general. The identities and characteristics of agent types were based on a meta-analysis of European land uses (van Vliet et al. 2015). Full productivity parameterisations are given in Tables S1a and b (Online Resource 1) and behavioural parameterisations in Online Resources 2-9.

\section{Scenarios}

Scenarios were used to provide dynamic and realistic contexts for our simulations, allowing us to explore behavioural effects across a range of relevant land use drivers and conditions. Each of the modelled worlds was allowed to develop through time according to implementations of the IPCC SRES scenarios A1, A2, B1 and B2 (Nakicenovic et al. 2000). These scenarios were first interpreted for the context of European land use change through expert and stakeholder analysis (Paterson et al. 2012) and then processed by a chain of 'top-down' land use models to produce a comprehensive, quantitative set of conditions (Lotze-Campen et al. 2012, 2013). Following this, the scenarios were translated into CRAFTY model parameters as fully as possible (see Table 1). This translation incorporated factors related to changes in climate, demography, technology (affecting agricultural yields), subsidies, economics, behaviour, trade systems and demand levels for different ecosystem services. Each scenario was simulated over the period 2010-2040.

\section{Behaviour}

In addition to the behavioural conditions implemented as part of each scenario (which determined the willingness of particular agent types to change land use and their sensitivity to certain capitals; Tables 1 and S4), a set of experimental behavioural variations was simulated within each scenario (Table 2). These were used to explore the effects of agents' sensitivity to levels of service supply and demand, their ability to produce multiple services simultaneously, their willingness to abandon their land use or change to an alternative land use, the diffusion of technology through social networks and individual-level variation in agent characteristics. These broad classes of behaviour were not intended to replicate specific properties of individual land managers but to represent a range of relevant characteristics, such as dedication to land management as a result of personal or cultural circumstances, reliance on profits from service production or willingness to adopt new technology (Murray-Rust et al. 2014).

Every possible combination of the selected behavioural parameter values was simulated, giving 64 distinct model parameterisations in each appropriate setting. Together, these allowed an assessment of the form and relative magnitude of important kinds of behaviour within scenario-specific contexts. We did not attempt to investigate any absolute magnitude of behavioural effects in this stylised system, but used the behavioural variations to investigate the direction of effects and model sensitivity to these (see Table S5, Online Resource 1 for details of parameter variations and Online Resources 2-9 for parameter values for each agent type).

\section{Simulation schedule}

In order to fully explore the effects of behavioural variations and their sensitivity to world and scenario characteristics, we ran the behavioural parameter setting combinations described above in each appropriate world, scenario and regionalisation combination. This gave a complete set of 1024 simulations (512 per world) (Table S5, Online Resource 1). Each simulation was run over 30 time steps, to represent the 30 year interval between 2010 and 2040 over which scenario and vision definitions applied. In each world, a common starting point for simulations was generated by averaging the planned variations of each model parameter and allowing an initial assignment of agents to develop according to these average values under 2010 conditions (i.e. average values of numerical parameters and average form of functional parameters). Model results were therefore all interpretable in terms of direction of change, for consistency with visions and any relevant real-world results.

\section{Visions}

Visions of European land systems were previously generated through a stakeholder-led process of normative foresight, described in detail by Pérez-Soba et al. (2015). A diverse group of 69 stakeholders, with interests in nature conservation, recreation, agriculture, forestry, urban planning, energy and water, met in a series of two-day workshops to develop 15 integrated land use vision for Europe in 2040. These visions were then clustered into three 'consolidated visions' (Best Land in Europe, Regional Connected, Local Multifunctional), which were refined in collaboration with a subset of the original stakeholders. The final visions provide coherent but contrasting caricatures of future land use in Europe, covering a spectrum of normative worldviews and desires of European land use stakeholders.

In order to allow for quantitative comparisons between our simulation results and the consolidated visions, we defined the latter via 9 metrics describing their principal spatial and nonspatial characteristics, as identified from the detailed vision descriptions (Pérez-Soba et al. 2015). These metrics described the extent, connectivity, diversity, 


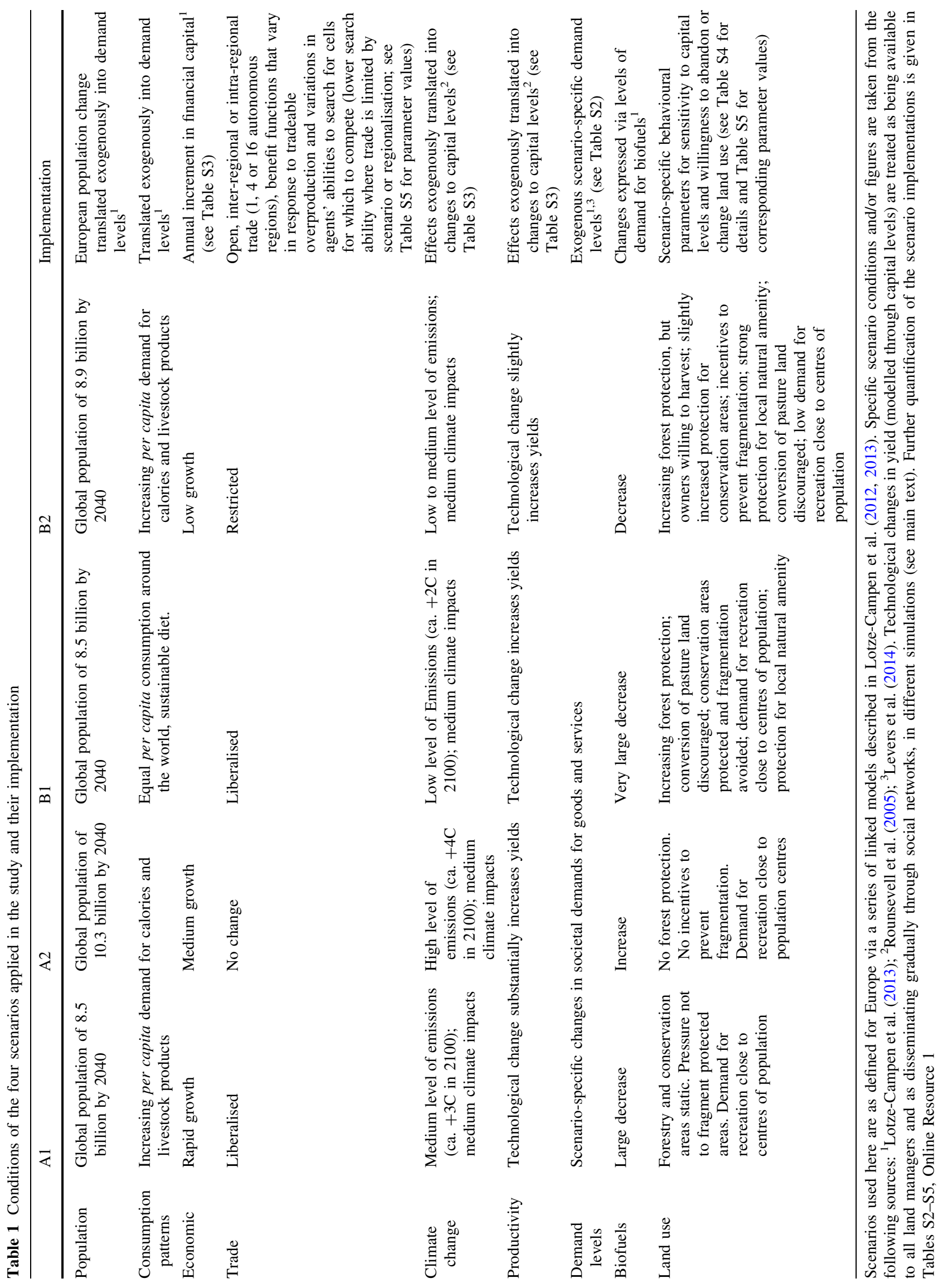


Table 2 Behavioural variations explored in the simulations

\begin{tabular}{|c|c|c|}
\hline Parameter & Variation (settings) & Interpretation \\
\hline Benefit function & $\begin{array}{l}\text { Linear/exponential form } \\
\text { of function }\end{array}$ & $\begin{array}{l}\text { Benefit functions give the value of a certain level of production under a certain level of unmet } \\
\text { demand and are the basis on which agents compete for land. This variation alters agents' } \\
\text { sensitivities to over- and under-production of services, with a linear form being more sensitive } \\
\text { when supply nearly equals demand and penalising overproduction, which an exponential form } \\
\text { does not. These are used to represent differences in the profit sensitivity of land managers that } \\
\text { may arise from the level of individual resources, dedication to land use or other (e.g. cultural) } \\
\text { pressures for production, or to represent circumstances in which surplus production can be } \\
\text { traded with other regions that are not explicitly modelled (i.e. open trading systems) }\end{array}$ \\
\hline Multifunctionality & On/off & $\begin{array}{l}\text { Controls the ability of agents to produce multiple goods and services simultaneously. } \\
\text { Monofunctional agents specialise and can produce greater quantities of single services, while } \\
\text { multifunctional agents diversify and produce lesser quantities of more than one service }\end{array}$ \\
\hline $\begin{array}{l}\text { Abandonment } \\
\text { threshold }\end{array}$ & Low/high & $\begin{array}{l}\text { Represents the willingness of land managers to abandon their current land use as a result of low } \\
\text { benefit values. A low threshold indicates dedication to the current land use; a high threshold } \\
\text { indicates strong sensitivity to benefit values. (spontaneous abandonment through lack of } \\
\text { succession or similar is not explicitly modelled) }\end{array}$ \\
\hline $\begin{array}{l}\text { Competition } \\
\text { threshold }\end{array}$ & Low/high & $\begin{array}{l}\text { Represents the willingness of land managers to implement an alternative land use with higher } \\
\text { benefit values than their own. High values indicate unwillingness to alter land use, even when } \\
\text { more profitable alternatives exist }\end{array}$ \\
\hline Social networks & On/off & $\begin{array}{l}\text { Technological increases in agricultural yields are disseminated through social networks when } \\
\text { they are activated, representing the diffusion of knowledge by interpersonal contacts. When } \\
\text { social networks are not activated, technology reaches all agents simultaneously }\end{array}$ \\
\hline $\begin{array}{r}\text { Individual } \\
\text { variation }\end{array}$ & On/off & $\begin{array}{l}\text { Controls whether agents are homogeneous or heterogeneous within their types. Heterogeneity } \\
\text { occurs in productive abilities and abandonment and competition thresholds }\end{array}$ \\
\hline
\end{tabular}

Every possible combination of behavioural settings $\left(2^{6}=64\right.$ in total) was used in each appropriate scenario, regionalisation and modelled world combination, as explained in the main text. The variations occur in addition to the scenario-specific behaviours described in Tables 1 and S4, meaning that 'low' and 'high' threshold settings do not necessarily take the same values in different scenarios. Further details are given in Table S5, Online Resource 1

productive efficiency and service provision of land management and were selected in order to assess each characteristic as comprehensively and independently as possible (Tables 3, 4). These characteristics were expressed relative to current conditions and were therefore independent of setting. Definitions took account of the direction and importance of any changes required by the consolidated visions. Descriptions of the consolidated visions and their translation into metrics are given in Table 4.

\section{Analysis}

The metrics described in Table 3 were calculated at every tenth time step of every simulation, giving values for each metric at 2020, 2030 and 2040 (2010 values were all equal to 1 as metrics were calculated relative to initial conditions). Agreement with consolidated visions was determined by the direction and magnitude of change of the metrics' values away from 1. Basic agreement was checked in terms of the simulations' abilities to simultaneously satisfy all of the conditions of each particular vision. Subsequently, using the definitions given in Table 4, each set of results was scored for its level of agreement with each vision. First, every metric with a direction of change that agreed with the relevant condition of the vision was given a score of 1 , and this was then multiplied by the importance of the condition to the vision (Table 4). Second, magnitudes of the metrics were scaled to the interval $[0,1]$ where 0 represented no change from initial conditions and 1 represented the greatest magnitude of change found across the results (either the maximum or minimum value of the metric, depending on the required direction of change). These scaled values were then also multiplied by the importance of the condition to the vision and added to the existing scores.

In this way, each simulation was assigned a score for each consolidated vision with half of the score depending upon the satisfaction of the directional changes required by the visions and half depending on the scale of these changes. The simulations that were judged to be most successful were therefore those that maximised the number of conditions satisfied and the amount of change towards those conditions (with more important conditions carrying more weight). The final results presented below are for 2040, when vision definitions apply. 


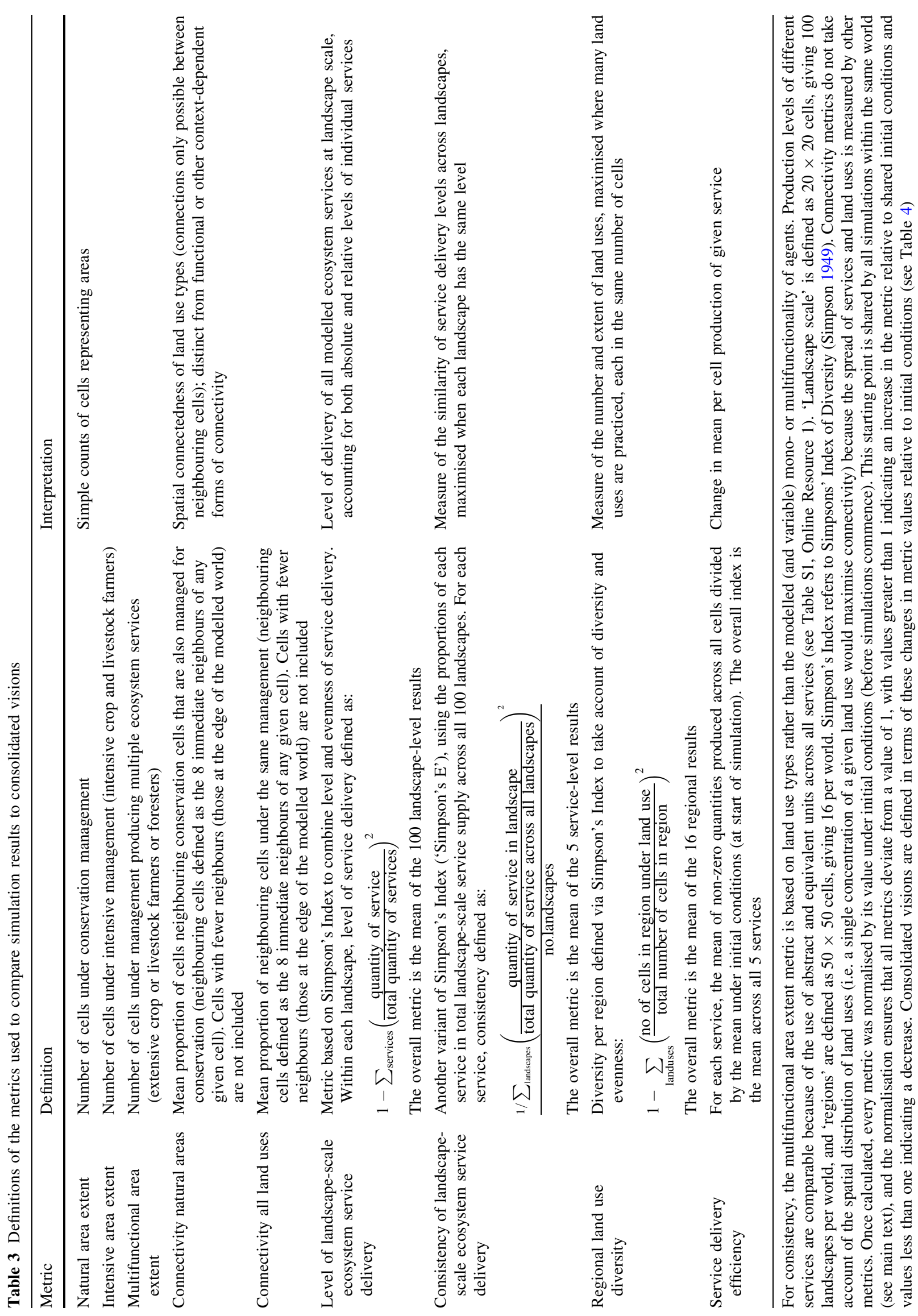


Table 4 Outline descriptions of the consolidated visions and their translation into land use metrics (metrics are defined in Table 3)

\begin{tabular}{|c|c|c|c|}
\hline & Best Land in Europe & Regional Connected & Local Multifunctional \\
\hline Outline & $\begin{array}{l}\text { Optimal use of land to ensure maximum } \\
\text { production of food and other natural } \\
\text { products. Land across the EU is matched } \\
\text { to the most appropriate use }\end{array}$ & $\begin{array}{l}\text { Society's needs are met regionally in } \\
\text { a coherent relationship between } \\
\text { people and their resources. In a } \\
\text { nonglobalised economy, there is a } \\
\text { move away from regional } \\
\text { specialisation }\end{array}$ & $\begin{array}{l}\text { Land functions are localised in small } \\
\text { areas based on innovative } \\
\text { approaches to living, working and } \\
\text { recreation. There is high diversity } \\
\text { in goods and services, land use and } \\
\text { society }\end{array}$ \\
\hline $\begin{array}{l}\text { Natural area } \\
\text { extent }\end{array}$ & +1 & +4 & +2 \\
\hline $\begin{array}{l}\text { Intensive area } \\
\text { extent }\end{array}$ & -1 & -2 & -4 \\
\hline $\begin{array}{l}\text { Multifunctional } \\
\text { area extent }\end{array}$ & 0 & +3 & +5 \\
\hline $\begin{array}{l}\text { Connectivity } \\
\text { natural areas }\end{array}$ & -2 & +5 & +3 \\
\hline $\begin{array}{l}\text { Connectivity all } \\
\text { land uses }\end{array}$ & +4 & +5 & +4 \\
\hline $\begin{array}{l}\text { Level of } \\
\text { landscape-scale } \\
\text { ecosystem } \\
\text { service delivery }\end{array}$ & +1 & +4 & +5 \\
\hline $\begin{array}{l}\text { Consistency of } \\
\text { landscape-scale } \\
\text { ecosystem } \\
\text { service delivery }\end{array}$ & -3 & +5 & +4 \\
\hline $\begin{array}{l}\text { Regional land use } \\
\text { diversity }\end{array}$ & +2 & +4 & 0 \\
\hline $\begin{array}{l}\text { Service delivery } \\
\text { efficiency }\end{array}$ & +3 & +3 & +4 \\
\hline
\end{tabular}

Values represent the direction (positive or negative) of change in metric values relative to initial conditions required to satisfy each vision and also the importance of this change $(0=$ irrelevant to vision, $5=$ very important to vision). Numerical values do not, therefore, indicate a magnitude of change required to satisfy each vision; magnitudes of changes are taken into account in the final analysis (see main text). Full descriptions of each vision are given in Pérez-Soba et al. (2015)

\section{Results}

\section{Relationships between metrics}

The nine metrics used in this study and the land use characteristics they describe are not fully independent of one another, and several are closely associated (Table 3). In order to understand pathways towards the consolidated visions, it is therefore necessary to assess the coherence of each vision as revealed by the relationships between metrics. Pearson's correlation coefficients calculated across all 1024 initial simulations revealed a number of strong positive and negative relationships (Table S6a, Online Resource 1). These fell into broad groups that illustrate fundamental relationships between the metrics. Positive relationships were found between intensive area extent, natural area extent and the connectivity and efficiency of all land uses. Each of these metrics had negative relationships with the level and consistency of landscape-scale ecosystem service delivery and regional land use diversity. In contrast, multifunctional area extent had positive relationships with landscape-scale ecosystem service delivery and regional land use diversity and negative relationships with the connectivity and productive efficiency of land uses.

These relationships, found consistently across all simulations, indicate a basic tension between production levels at local and global scales. Global intensification and specialisation maximised productivity, leaving larger areas spare for other uses, while local multifunctionality ensured consistent delivery of ecosystem services across space. All but one of the relationships were consistent in both of the modelled worlds (Tables S6b, c), though in World B positive associations between intensive area extent, natural area extent and land use efficiency were stronger, and negative associations between global and local metrics were weaker. These relationships affect the coherence of all consolidated visions, and particularly those that place great importance on increases in both global characteristics 


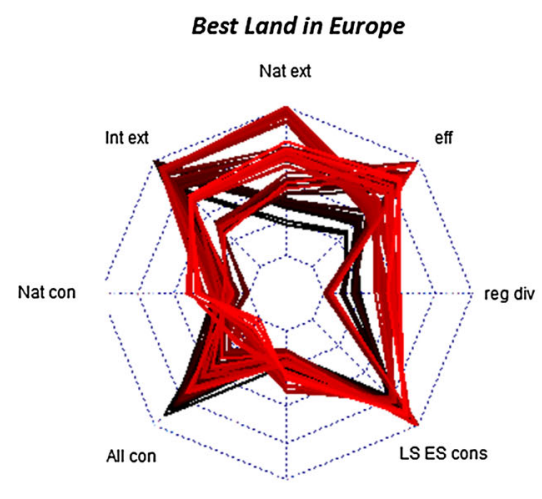

LSES level

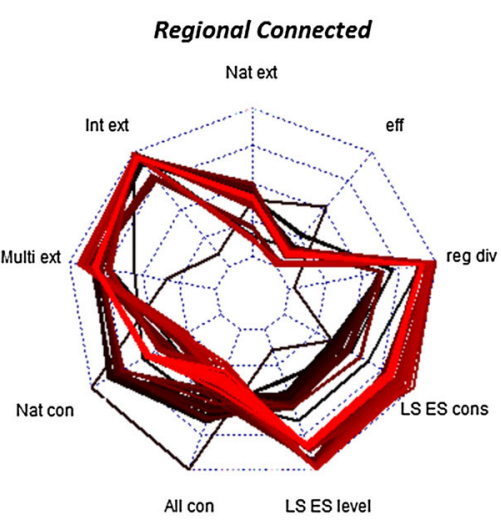

Local Multifunctional

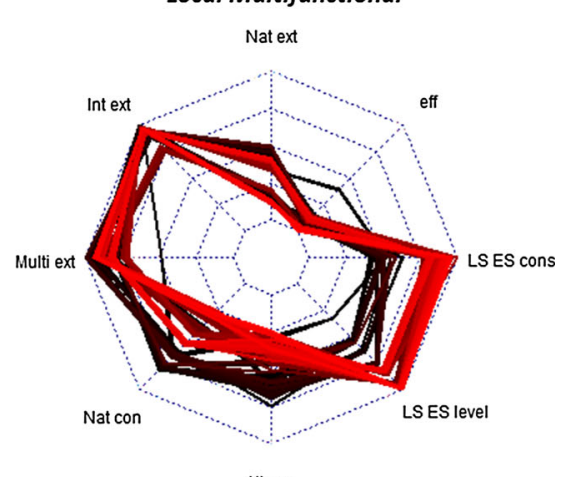

Fig. 1 Plots of the 100 highest-scoring simulations for each consolidated vision showing agreement with each of the conditions of each vision. Agreement with each condition is maximised at the outer edge of the plot and minimised in the centre (whatever the direction of change required by the vision; Table 4). Axes run from the lowest level of agreement found across all 1024 simulations (at the centre) to the highest level of agreement found across all 1024 simulations (at the outer edge). Individual metrics are related (Table S6), so that axes are not all independent. Individual simulation results are colour-coded

such as connectivity or land use efficiency and local characteristics such as ecosystem service delivery (e.g. Best Land in Europe).

\section{Agreement with visions}

The above relationships limit the extent to which agreement with the consolidated visions can be achieved, and our results showed that no simulations approached complete agreement with any vision. Instead, (partial) achievement of the visions depended upon trade-offs between different conditions. In terms of the scores we calculated, the most successful simulations reached approximately half of the potential score for each vision.

Plots of agreement with each condition of each vision make the trade-offs between these conditions clear (Fig. 1). In the case of Regional Connected, the highest-scoring simulations were those that maximised local-scale requirements by minimising intensive area extent and producing high levels of multifunctional area extent, landscape-scale ecosystem service delivery levels and consistency, and regional land use diversity. These metrics took high values at the expense of natural area extent, land use efficiency and connectivity. Another group of highscoring results produced higher connectivity values but lower landscape and regional-scale metric values. Very similar trade-offs were found in results for Local Multifunctional. Agreement with Best Land in Europe, in contrast, was maximised by results with low levels of landscape-scale ecosystem service delivery consistency and intermediate values of land use extents, efficiency and at equal steps along a black-red gradient, with the result most closely agreeing with the vision being red, and the result with the 100th best agreement being black. Metrics are abbreviated as follows: Nat ext natural area extent, eff land use efficiency, reg div regional land use diversity, LS ES cons landscape-level ecosystem service delivery consistency, LS ES level landscape-level ecosystem service delivery level, All con connectivity of all land uses, Nat con connectivity of natural areas, Multi ext extent of multifunctional areas, Int ext extent of intensive areas

connectivity. Trade-offs between conditions were particularly strong in this vision, with the opposing requirements for landscape-scale ecosystem service delivery level and consistency, and for the connectivity of natural and other areas, proving impossible to reconcile in our simulations.

\section{Experimental effects}

Within the ranges identified above, the extent to which visions were achieved was most strongly affected by world design (Worlds A and B), scenario (A1, A2, B1 and B2) and regionalisation $(1,4$ or 16 regions, representing extent of free trade). These factors had large and dominant effects that often obscured the results of experimental variations in modelled behaviour. Both modelled worlds gave similar relative values of the metrics, but different absolute values. Ranges and maximum values were both largest in World A, except for metrics measuring connectivity and efficiency, producing the highest individual (if not mean) scores for each vision (Figs. S2 \& S6). In particular, World A was able to produce by far the highest and most consistent values for local and regional metrics of ecosystem service supply, without equivalent sacrifices in global-scale metrics.

Increasing regionalisation, interpretable as increasing restriction of inter-regional trade, had a number of effects on the ranges of values taken by the metrics (Fig. S3, Online Resource 1). The total extent of natural areas decreased dramatically with increasing regionalisation, and smaller decreases occurred in connectivity and intensive area extent. However, levels of delivery and diversity of 
ecosystem services at sub-global scales were maximised in the most regionalised system. Changes in scenario also had substantial effects, except on connectivity metrics (Fig. S4, Online Resource 1). Most distinct was the A1 scenario, which maximised the extents of natural and intensive areas and minimised the extent of multifunctional areas. In common with scenario B1, it also minimised sub-globalscale metrics. Scenario B1 produced the lowest values for land use efficiency, but otherwise resembled A1 in terms of sub-global characteristics and A2 and B2 in terms of global characteristics. Scenarios A2 and B2 were characterised by results that maximised either multifunctional area extent and sub-global metrics, or intensive area extent, land use efficiency and connectivity. These scenarios produced the highest scores for Regional Connected and Local Multifunctional, while scenario A1 produced the best scores for vision Best Land in Europe.

The effects of modelled (scenario-independent) agent behaviours were less clear than those of world, scenario and regionalisation. This was partly because they were weaker, under the settings used here, and partly because their strength, direction and sensitivity to other parameters (visible in modalities of output values) were all strongly context-dependent (Table S8 and e.g. Fig S5, Online Resource 1). Some overall effects on values taken by the metrics were apparent (Table S7, Online Resource 1), but the extent to which these persisted and contributed to achievement of the visions varied substantially in different contexts. For example, the fundamental trade-off between global- and local-scale ES provision was affected by behavioural settings, but in complex and often unexpected ways, even in specific contexts (Fig S7, Online Resource 1). Nevertheless, the settings that produced the broadest range of consolidated vision score values also produced the best values in almost every case, suggesting that behaviours with the greatest influence tended to slow the rate of modelled land use change. This was especially true in the case of social networks, where the gradual diffusion of technological increases in yields constrained the extent of both agreement and disagreement with the visions, simultaneously increasing sensitivity to other parameters. Overall, the impacts of modelled behaviours (summarised in Table S8, Online Resource 1) were greatest when they had the effect of slowing the momentum of other drivers of land use change, for example when raised competition thresholds limited the homogenisation of land use and improved scores for Regional Connected.

\section{Achievement of visions}

Together, these results illuminate potential pathways to achievement of the consolidated visions, by allowing the identification of conditions which maximise agreement with each vision (Fig. 2, Table S9, Online Resource 1). The strongest and most consistent of these relate to world, scenario and regionalisation, with scenarios and regionalisations that limit trade and rates of change maximising agreement with Regional Connected and Local Multifunctional, and opposite conditions maximising agreement with Best Land in Europe. Within these fixed contexts, definable sets of behaviour either increase or decrease agreement with visions, with different sets playing similar roles in different contexts.

These contrasting sets of behaviour primarily differed in their implications for the speed and consistency of change. For example, in the circumstances that produced the highest scores for Regional Connected (World A, scenario B2, 16 regions), agents that respond quickly but differently to changes in context maximised scores, while in the circumstances that produce the lowest scores (World B, scenario B1, 1 region), agents that respond slowly but consistently maximised scores (Table S9, Online Resource 1). There were some behaviours that had general effects, however; monofunctionality of production always contributed to Regional Connected, while multifunctionality contributed to Local Multifunctional and Best Land in Europe because it reduced trade-offs between vision conditions. Linear benefit functions increased achievement of Best Land in Europe, while social networks and high competition thresholds increased achievement of Local Multifunctional.

\section{Discussion}

This study explored a number of uncertainties about the future development of simulated land systems in order to assess the achievability of stakeholder-developed visions of future land use in Europe. One important conclusion of this work is that the consolidated visions we analysed were not fully coherent or achievable, with a fundamental tension between small-scale land system multifunctionality and large-scale efficiency (i.e. between land sharing and land sparing) undermining several aspects of each vision. In particular, we found that the multifunctional landscapes preferred by stakeholders were not achievable under the assumptions of our model without substantial decreases in connectivity and overall production levels.

However, our findings also highlight major factors that decisively influence the feasibility of visions. The first relates to the exact requirements of each vision and the extent to which trade-offs between them are viewed as acceptable. It has been noted by others that decisionmakers often develop visions of complex systems without adequately considering such issues (e.g. Trutnevyte et al. 2012). In this case, stakeholders were explicitly asked not 


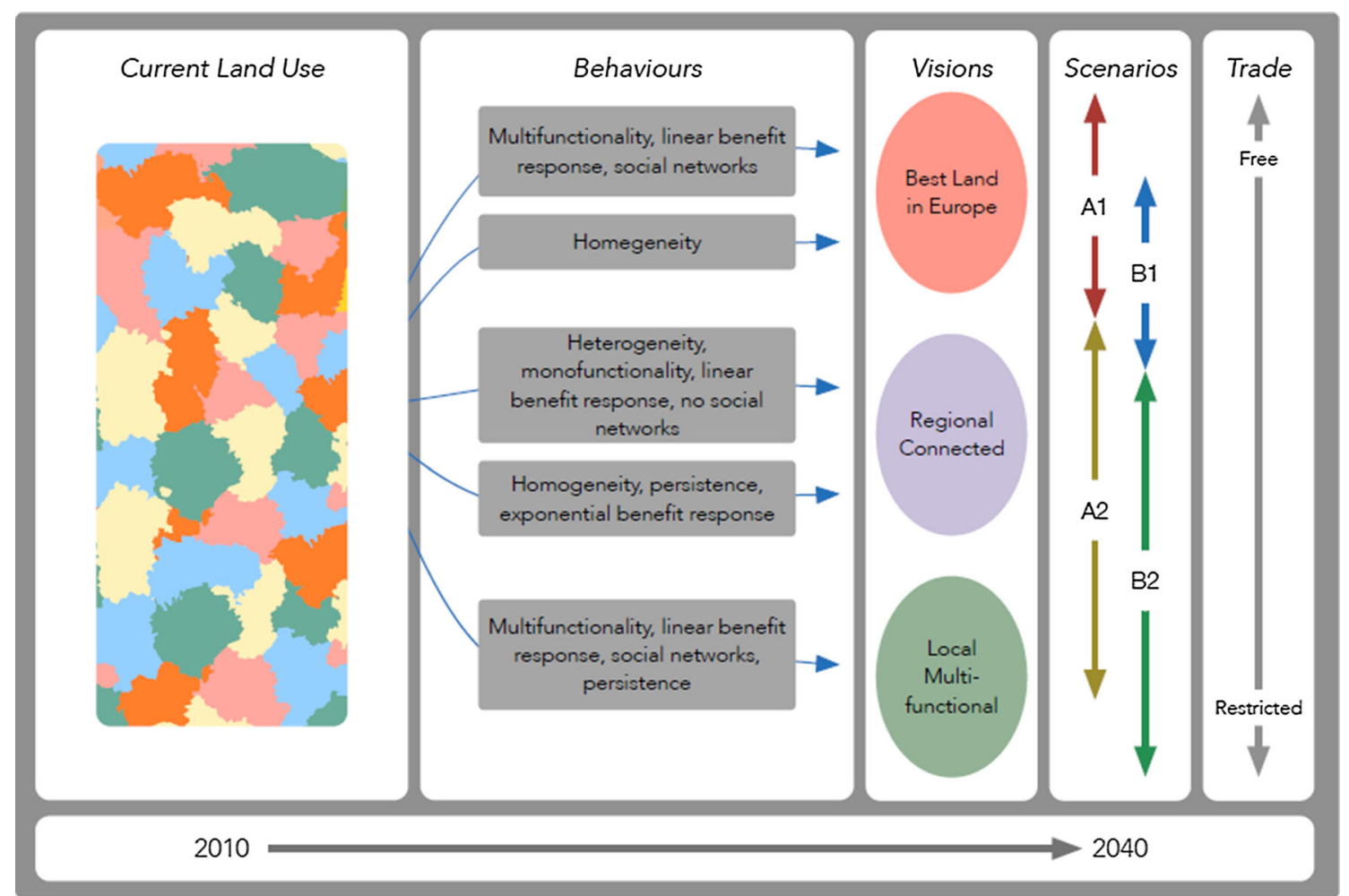

Fig. 2 Behavioural pathways to each of the consolidated visions. From a consistent starting point, pathways diverge according to scenario and trading conditions and according to more flexible behavioural effects. Behaviours identified in the figure are those that increase agreement with the relevant vision when scenario and trading conditions are favourable (arrows to top of vision ellipses) and when

to consider trade-offs but to follow their personal convictions and desires. Indeed, a major objective was to analyse trade-offs required in reaching the consolidated visions using the agent-based modelling approach reported here and a traditional top-down modelling approach reported elsewhere in this volume (and Lotze-Campen et al. 2012, 2013). Our results suggest that a long-term, iterative approach that involves stakeholders as well as modelling or analysis cycles appears particularly promising (if practically challenging) for future vision development (see also, e.g. Hewitt et al. 2014). This could also allow adjustments of the specific land system characteristics to be analysed (and, potentially, the metrics used in the analyses), in order to further explore trade-offs and to refine vision requirements.

Another factor is scenario design. Scenario conditions were found to be strong determinants of vision achievability, with climatic, economic or demographic conditions less conducive to intensification and specialisation of land uses better satisfying small-scale requirements of the visions. The lack of trade liberalisation and relatively small increases in economic growth, and agricultural yields in scenarios A2 and B2 supported the achievement of visions these conditions are unfavourable (arrows to bottom of vision ellipses). Behaviours and their effects are described in more detail in the main text and Tables 2 and S7-S9. Persistence here refers to abandonment and competition thresholds that favour persistence with agents' current land uses

with strong local to regional-scale requirements (Regional Connected and Local Multifunctional). Conversely, strong economic growth, yield increases and trade liberalisation in scenario A1 provided the best setting for the achievement of visions that emphasise overall efficiency and specialisation (Best Land in Europe). However, variations in scenario conditions would shift the relationships we identify. For instance, a rapid growth in agricultural yields, if divorced from the trade liberalisation envisaged in scenario A1, would increase the feasibility of the Regional Connected and Local Multifunctional visions. Similarly, stronger policies for environmental protection would accord with several aspects of the visions. To some extent, such alternative scenarios are (perhaps legitimately) assumed in vision definitions.

A third factor relates to the impact of land uses on ecosystem services. For simplicity, we model broad, distinct land uses (and a single, restricted form of multifunctionality), and the validity and strength of the relationships we identify depend upon the relative provision of ecosystem services within each land use type. A key consideration is the magnitude and efficiency of production in multifunctional areas, particularly the extent to which 
these areas can sustain various agricultural and natural processes. Many empirical studies have focused on this (e.g. Phalan et al. 2011; Egan and Mortensen 2012; Grau et al. 2013), and it is strongly prioritised by stakeholders of all kinds (Pérez-Soba et al. 2015). Nevertheless, considerably more evidence is required for a robust assessment of vision achievability. Our results show that multifunctional production can, in principle, alter the extent of trade-offs between vision conditions, ensuring the provision of a range of ecosystem services at local-regional scales in more globalised land systems, but potentially leading to excessive inefficiency in regionalised systems.

The final factor with a decisive impact on system development is human behaviour. While socio-economic, climatic and trading conditions influenced land use outcomes most strongly in our simulations, they may be particularly hard to shape in reality. Behavioural effects, in contrast, were found to be weaker and less consistent, but may represent more easily exploitable pathways towards visions, especially at smaller scales. Many of the behaviours we simulated had the effect of altering sensitivity to other factors and as such could play a role in accentuating or mitigating the impacts of broad or fixed conditions. This was especially true of social networks, which, when used to spread knowledge or technology allowing increases in agricultural yields, controlled the momentum of changes driven by other conditions. Across all simulations, more effective dissemination of yield increases improved the responsiveness of the agricultural land systems to prevailing conditions, particularly where those conditions favoured intensification and specialisation of these land uses. Similarly, a lack of sensitivity to demand levels, representing personal, social, cultural or financial support for overproduction of services, limited the impact of scenario conditions. This was also true of the thresholds that described agents' willingness to abandon their land use or to switch to another; the more dedicated agents were to an existing land use, even where more profitable alternatives existed, the slower the rate of land use change. Variation between agents was found to be beneficial in circumstances that were already otherwise favourable to vision conditions because it reduced the severity of trade-offs with the secondary vision requirements but, in unfavourable conditions, homogenous populations that consistently resisted drivers of change were more successful.

Together, these findings illuminate some of the important effects that individual-level behaviour can have on development of the land system. However, our results are illustrative and tentative. We use empirically based assumptions about forms of behaviour, but do not explore alternative assumptions. We also do not consider a range of potentially important behaviours, including individual and societal responses to anthropogenic environmental change, particularly demand-side effects of consumer preferences for particular methods or locations of production. Indeed, social uncertainties in projections of future conditions may well be greater than biophysical uncertainties, especially when highly complex and nonlinear feedbacks within and between human and natural systems are taken into account (e.g. Pelling and Dill 2009; Hostert et al. 2011). Perhaps most importantly, we leave assessments of the translation of the effects identified here into real-world contexts to future studies.

Nevertheless, these issues do not necessarily reduce the generality of our findings. Particularly important to note is that our simulations were designed so that demands for all ecosystem services could be satisfied simultaneously, minimising the strength of trade-offs. Greater pressure on the land system in real-world contexts (especially given the rapid population growth assumed in scenarios A2 and B2) can be expected to substantially shift the balance between different conditions of the visions and make these tradeoffs more extreme. Furthermore, our findings were consistent in both of the highly divergent 'worlds' we modelled (Table S6), suggesting that further variations in the patterns and dependencies of productivity may have relatively minor effects. Indeed, real-world complexities may act to increase the likelihood or severity of trade-offs, given that the greatest diversity of outcomes (and hence scope for changing land system characteristics) was generated here by the artificially homogeneous World A.

Overall, our findings suggest that land management policies should focus on strongly influential factors related to socio-economic, climatic and trading conditions (along with, as far as possible, the spatial configuration of natural and human capitals supporting ecosystem service provision, as explored in our world designs). Consistently with previous findings (e.g. Dibden and Cocklin 2009; Brown et al. 2014), limitations on trade between regions improve the diversity and consistency of ecosystem service delivery at small scales and provide the quickest route to several landscape characteristics prioritised by stakeholders. The consequent decreases in overall productive efficiency and connectivity remain uncertain, but have important implications, especially for natural areas, making the viability and perceived importance of these areas crucial factors in any attempt to balance small- and large-scale land system characteristics (Phalan et al. 2011; Seppelt et al. 2013).

Improved understanding of land system development clearly requires more knowledge and modelling of behavioural processes, especially those related to social networks, sensitivities to environmental or socio-economic change and motivations for land management (e.g. Maertens and Barrett 2013; Magliocca et al. 2013). The integration of these into scenario studies, particularly involving exploratory modelling, is also a priority (Rial et al. 2004; 
Pontius et al. 2008; Kok et al. 2015). These are important steps towards more robust development of scenarios, visions and governance strategies for land systems.

\section{Conclusion}

We find that a number of uncertainties affect attempts to anticipate or shape future land use changes. In particular, the omission of behavioural processes (endogenous drivers) from scenarios and scenario-based modelling may substantially constrain understanding. While climatic and socio-economic conditions inevitably play dominant roles in land system developments, considerable scope exists for behaviourally driven variation within these broad limits. The context dependency of behavioural effects also means that they can accelerate, counteract or mitigate the impacts of other drivers. Therefore, further model-based experimentation, in stylised and real-world settings, may be of great help in reducing uncertainties and exploring potential pathways to desired future conditions.

Notwithstanding poorly understood behavioural effects, some trade-offs in land characteristics appear inevitable, particularly between the contrasting local-scale and globalscale characteristics generally favoured by stakeholders. However, the strength of these trade-offs depends upon uncertain characteristics of scenarios and land uses that, in particular, determine the potential for multifunctional production of ecosystem services. These characteristics therefore represent an appropriate focus for research and vision development, allowing the identification of tradeoffs that are least extreme, most acceptable and most susceptible to adjustment through behavioural or other influences. When combined with behaviourally explicit scenarios and modelling, this would assist governance strategies to be more realistic and holistic, utilising a wide range of established and novel tools to achieve their objectives.

Acknowledgments This work was carried out as part of the Visions of Land Use Transitions in Europe (VOLANTE) project (http://www. volante-project.eu/), funded by the European Commission under the Environment (including climate change) Theme of the 7th Framework Programme for Research and Technological Development: Volante FP7-ENV-2010-265104, and the Impacts And Risks From High-End Scenarios: Strategies For Innovative Solutions (IMPRESSIONS) project (http://www.impressions-project.eu/), funded by the European Union's Seventh Programme for research, technological development and demonstration under Grant Agreement No 603416.

\section{Compliance with ethical standards}

Conflict of interest The authors declare that they have no conflict of interest.
Open Access This article is distributed under the terms of the Creative Commons Attribution 4.0 International License (http://crea tivecommons.org/licenses/by/4.0/), which permits unrestricted use, distribution, and reproduction in any medium, provided you give appropriate credit to the original author(s) and the source, provide a link to the Creative Commons license, and indicate if changes were made.

\section{References}

Alexander P, Moran D, Rounsevell MDA, Smith P (2013) Modelling the perennial energy crop market: the role of spatial diffusion. J R Soc Interface. doi:10.1098/rsif.2013.0656

Arneth A, Brown C, Rounsevell MDA (2014) Global models of human decision-making for land-based mitigation and adaptation assessment. Nature Clim Change 4:550-557. doi:10.1038/ nclimate 2250

Barnosky AD, Hadly EA, Bascompte J, Berlow EL, Brown JH, Fortelius M, Getz WM, Harte J, Hastings A, Marquet PA, Martinez ND, Mooers A, Roopnarine P, Vermeij G, Williams JW, Gillespie R, Kitzes J, Marshall C, Matzke N, Mindell DP, Revilla E, Smith AB (2012) Approaching a state shift in Earth's biosphere. Nature 486:52-58. doi:10.1038/nature11018

Berger T (2001) Agent-based spatial models applied to agriculture: a simulation tool for technology diffusion, resource use changes and policy analysis. Agric Econ 25:245-260. doi:10.1111/j. 1574-0862.2001.tb00205.x

Brown C, Murray-Rust D, van Vliet J, Alam SJ, Verburg PH, Rounsevell MD (2014) Experiments in globalisation, food security and land use decision making. PLoS ONE 9:e114213. doi:10.1371/journal.pone. 0114213

de Chazal J, Rounsevell MDA (2009) Land-use and climate change within assessments of biodiversity change: a review. Glob Environ Change 19:306-315. doi:10.1016/j.gloenvcha.2008.09. 007

Dibden J, Cocklin C (2009) 'Multifunctionality': trade protectionism or a new way forward? Environ Plan A 41:163-182. doi:10. 1068/a40127

Dubrovsky M, Trnka M, Holman I, Svobodova E, Harrison P (2015) Developing a reduced-form ensemble of climate change scenarios for Europe and its application to selected impact indicators. Clim Change 128:169-186. doi:10.1007/s10584-014-1297-7

Egan JF, Mortensen DA (2012) A comparison of land-sharing and land-sparing strategies for plant richness conservation in agricultural landscapes. Ecol Appl 22:459-471. doi:10.1890/110206.1

Evans TP, Phanvilay K, Fox J, Vogler J (2011) An agent-based model of agricultural innovation, land-cover change and household inequality: the transition from swidden cultivation to rubber plantations in Laos PDR. J Land Use Sci 6:151-173. doi:10. 1080/1747423X.2011.558602

Filatova T, Polhill G (2012) Shocks in coupled socio-ecological systems: what are they and how can we model them? In: Managing resources of a limited planet, sixth biennial iEMSs meeting, Leipzig, Germany, pp. 2619-2630

Gotts NM (2007) Resilience, panarchy, and world-systems analysis. Ecol Soc 12(1):24

Grau R, Kuemmerle T, Macchi L (2013) Beyond 'land sparing versus land sharing': environmental heterogeneity, globalization and the balance between agricultural production and nature conservation. Curr Opin Environ Sustain 5:477-483. doi:10.1016/j. cosust.2013.06.001 
Hansen AJ, Neilson RP, Dale VH, Flather CH, Iverson LR, Currie DJ, Shafer S, Cook R, Bartlein PJ (2001) Global change in forests: responses of species, communities, and biomes: interactions between climate change and land use are projected to cause large shifts in biodiversity. Bioscience 51:765-779. doi:10.1641/00063568(2001)051[0765:gcifro]2.0.co;2

Harrison PA, Dunford R, Savin C, Rounsevell MDA, Holman IP, Kebede AS, Stuch B (2015) Cross-sectoral impacts of climate change and socio-economic change for multiple, European landand water-based sectors. Clim Change 128:279-292. doi:10. 1007/s10584-014-1239-4

Hewitt R, van Delden H, Escobar F (2014) Participatory land use modelling, pathways to an integrated approach. Environ Model Softw 52:149-165. doi:10.1016/j.envsoft.2013.10.019

Hostert PKT, Prishchepov A, Sieber A, Lambin EF, Radeloff VC (2011) Rapid land use change after socio-economic disturbances: the collapse of the Soviet Union versus Chernobyl. Environ Res Lett 6:045201. doi:10.1088/1748-9326/6/4/045201

IPCC (2012) Managing the risks of extreme events and disasters to advance climate change adaptation: special report of the Intergovernmental Panel on Climate Change. Cambridge University Press, Cambridge

Knutti R, Sedlacek J (2013) Robustness and uncertainties in the new CMIP5 climate model projections. Nature Clim Change 3:369-373. doi:10.1002/grl.50256

Knutti R, Masson D, Gettelman A (2013) Climate model genealogy: generation CMIP5 and how we got there. Geophys Res Lett 40:1194-1199. doi:10.1002/grl.50256

Kok K, Bärlund I, Flörke M, Holman I, Gramberger M, Sendzimir J, Stuch B, Zellmer K (2015) European participatory scenario development: strengthening the link between stories and models. Clim Change 128:187-200. doi:10.1007/s10584-014-1143-y

Kriegler E, O’Neill BC, Hallegatte S, Kram T, Lempert RJ, Moss RH, Wilbanks T (2012) The need for and use of socio-economic scenarios for climate change analysis: a new approach based on shared socio-economic pathways. Glob Environ Change 22:807-822. doi:10.1016/j.gloenvcha.2012.05.005

Lambin EF, Meyfroidt P (2010) Land use transitions: socio-ecological feedback versus socio-economic change. Land Use Policy 27:108-118. doi:10.1016/j.landusepol.2009.09.003

Lescovec J, Kleinberg J, Faloutsos C (2007) Graph evolution: densification and shrinking diameters. ACM Trans Knowl Discov Data 1:1-41

Levers C, Verkerk PJ, Müller D, Verburg PH, Butsic V, Leitão PJ, Lindner M, Kuemmerle T (2014) Drivers of forest harvesting intensity patterns in Europe. For Ecol Manage 315:160-172. doi:10.1016/j.foreco.2013.12.030

Lotze-Campen H, Popp A, Verburg P, Lindner M, Verkerk H, Helming J, Tabeau A, Lavalle C (2012) Description of the linked modelling system of sector models and multi-sector assessments. VOLANTE Project Deliverable. Available at: http://www. volante-project.eu/images/stories/DELIVERABLES/ VOLANTE_D7.2_Description_of_the_linked_modelling_sys tem_of_sector_models_and_multi-sector_assessments.pdf

Lotze-Campen H, Popp A, Verburg P, Lindner M, Verkerk H, Kakkonen E, Schrammeijer E, Schulp N, van der Zanden E, van Meijl H, Tabeau A, Helming J, Kuemmerle T, Lavalle C, Batista e Silva F, Eitelberg D (2013) Description of the translation of sector specific land cover and land management information. VOLANTE Project Deliverable. Available at: http://www. volante-project.eu/images/stories/DELIVERABLES/ VOLANTE_D7.3_Description_of_the_translation_of_sector specific_land_cover_and_management_information.pdf

Maertens A, Barrett CB (2013) Measuring social networks' effects on agricultural technology adoption. Am J Agric Econ 95:353-359. doi:10.1093/ajae/aas049
Magliocca NR, Brown DG, Ellis EC (2013) Exploring agricultural livelihood transitions with an agent-based virtual laboratory: global forces to local decision-making. PLoS ONE 8:e73241. doi:10.1371/journal.pone.0073241

Metzger MJ, Rounsevell MD, Van den Heiligenberg H, Pérez-Soba $\mathrm{M}$, Soto Hardiman P (2010) How personal judgment influences scenario development: an example for future rural development in Europe. Ecol Soc 15:5

Morgan MG, Keith D (2008) Improving the way we think about projecting future energy use and emissions of carbon dioxide. Clim Change 90:189-215. doi:10.1007/s10584-008-9458-1

Murray-Rust D, Brown C, van Vliet J, Alam SJ, Robinson DT, Verburg PH, Rounsevell M (2014) Combining agent functional types, capitals and services to model land use dynamics. Environ Model Softw 59:187-201. doi:10.1016/j.envsoft.2014.05.019

Nakicenovic N, Alcamo J, Davis G, de Vries B, Fenhann J, Gaffin S, Gregory K, Griibler A, Jung TY, Kram T, Lebre La Rovere E, Michaelis L, Mori S, Morita T, Pepper W, Pitcher H, Price L, Riahi K, Roehrl A, Rogner HH, Sankovski A, Schlesinger M, Shukla P, Smith S, Swart R, van Rooijen S, Victor N, Dadi Z (2000) In: Nakicenovic N, Swart R (eds) Special report on emissions scenarios special report on emissions scenarios, ISBN 0521804930 Cambridge University Press, Cambridge

Parker DC, Meretsky V (2004) Measuring pattern outcomes in an agent-based model of edge-effect externalities using spatial metrics. Agric Ecosyst Environ 101:233-250. doi:10.1016/j. agee.2003.09.007

Paterson JM, Metzger M, Walz A (2012) VOLANTE Deliverable 9.1: The VOLANTE scenarios: framework, storylines and drivers. VOLANTE Project deliverable. Available at: http://www. volante-project.eu/images/stories/DELIVERABLES/

VOLANTE_D9.1_The_VOLANTE_scenarios_framework_story lines_and_drivers.pdf

Pelling M, Dill K (2009) Disaster politics: tipping points for change in the adaptation of sociopolitical regimes. Prog Hum Geogr. doi:10.1177/0309132509105004

Pérez-Soba MP, Paterson J, Metzger M (2015) Visions of future land use in Europe: stakeholder visions for 2040. VOLANTE Project report. Alterra Wageningen UR, ISBN 978-94-6257-406-9. Available at: http://www.volante-project.eu/docs/visions.pdf

Phalan B, Onial M, Balmford A, Green RE (2011) Reconciling food production and biodiversity conservation: land sharing and land sparing compared. Science 333:1289-1291. doi:10.1126/science. 1208742

Pontius RG Jr, Boersma W, Castella JC, Clarke K, de Nijs T, Dietzel C, Duan Z, Fotsing E, Goldstein N, Kok K, Koomen E, Lippitt CD, McConnell W, Mohd Sood A, Pijanowski B, Pithadia S, Sweeney S, Trung T, Veldkamp AT, Verburg PH (2008) Comparing the input, output, and validation maps for several models of land change. Ann Reg Sci 42:11-37. doi:10.1007/ s00168-007-0138-2

Rial JA, Pielke RA Sr, Beniston M, Claussen M, Canadell J, Cox P, Held H, de Noblet-Ducoudré N, Prinn R, Reynolds JF, Salas JD (2004) Nonlinearities, feedbacks and critical thresholds within the earth's climate system. Clim Change 65:11-38. doi:10.1023/ B:CLIM.0000037493.89489.3f

Rounsevell MDA, Metzger MJ (2010) Developing qualitative scenario storylines for environmental change assessment. Wiley Interdiscip Rev Clim Change 1:606-619. doi:10.1002/wcc.63

Rounsevell M, Ewert F, Reginster I, Leemans R, Carter T (2005) Future scenarios of European agricultural land use: II. Projecting changes in cropland and grassland. Agric Ecosyst Environ 107:117-135. doi:10.1016/j.agee.2004.12.002

Rounsevell MDA, Arneth A, Alexander P, Brown DG, de NobletDucoudre N, Ellis E, Finnigan J, Galvin K, Grigg N, Harman I, Lennox J, Magliocca N, Parker D, O’Neill BC, Verburg PH, 
Young O (2014) Towards decision-based global land use models for improved understanding of the Earth system. Earth Syst Dyn 5:117-137. doi:10.5194/esd-5-117-2014

Rowlands DJ, Frame DJ, Ackerley D, Aina T, Booth BBB, Christensen C, Collins M, Faull N, Forest CE, Grandey BS, Gryspeerdt E, Highwood EJ, Ingram WJ, Knight S, Lopez A, Massey N, McNamara F, Meinshausen N, Piani C, Rosier SM, Sanderson BM, Smith LA, Stone DA, Thurston M, Yamazaki K, Hiro YY, Allen MR (2012) Broad range of 2050 warming from an observationally constrained large climate model ensemble. Nature Geosci 5:256-260. doi:10.1038/ngeo1430

Seppelt R, Lautenbach S, Volk M (2013) Identifying trade-offs between ecosystem services, land use, and biodiversity: a plea for combining scenario analysis and optimization on different spatial scales. Curr Opin Environ Sustain 5:458-463. doi:10. 1016/j.cosust.2013.05.002
Simpson EH (1949) Measurement of diversity. Nature 163:688. doi:10.1038/163688a0

Stainforth DA, Allen MR, Tredger ER, Smith LA (2007) Confidence, uncertainty and decision-support relevance in climate predictions. Philos Trans R Soc A Math Phys Eng Sci 365:2145-2161. doi:10.1098/rsta.2007.2074

Trutnevyte E, Stauffacher M, Scholz RW (2012) Linking stakeholder visions with resource allocation scenarios and multi-criteria assessment. Eur J Oper Res 219:762-772. doi:10.1016/j.ejor. 2012.01.009

van Vliet J, de Groot HL, Rietveld P, Verburg PH (2015) Manifestations and underlying drivers of agricultural land use change in Europe. Landsc Urban Plan 133:24-36. doi:10.1016/j.landurb plan.2014.09.001 